\section{THE SCIENTIFIC RELATIONS OF GERMANY, FRANCE, AND ENGLAND}

THE following extracts from M. Berthelot's recent excellent article in the Temps, on the Relations which should exist between Germany and France, are taken from a recent number of the Pharmaceutical Fournal:-

We know that modern civilisation depends upon three nations, which should at all times and at any cost remain united-namely, France, Germany, and England, each with its peculiar genius and its share in the historic development of the human race. From the seventeenth century each of these rations has taken an active and prominent part in the progress of science.

To speak first of physical and mathematical sciences. Though the initiative was due principally to a few men of other countries -Galileo, an Italian, and Copernicus, a Pole, being the founders of modern astronomy and mechanics-yet the development of these sciences was concentrated chiefly in France, Germany, and England. In France, Descartes discovered the methods of geometric analysis, which have proved more durable than his philosophical and cosmogonical theories. In Germany, Kepler invented the laws of planetary movemant; and Leibnitz, who by education and the clearness of his conceptions was perhaps more French than German, laid down the rules of the differential calculus under a form in which they still exist amongst us. At the same time, England produced Newton, greater, perhaps, in the science of nature than either Descartes, Kepler, or Leibnitz; for Newton discovered both new methods of calculation and the laws of astronomy, and since his time we have scarcely done more than develop his ideas and doctrines in studying the movement of the stars.

This same concourse of the three great nations of modern times is seen also in the foundation of chemical science, which in the present day plays so important a part, whether it be in the theories relative to atoms and the constitution of matter, to the formation of stars and of the successive layers of the terrestrial globe, to the origin of life itself ; or, on the other hand, in the applications of human industry, dealing with metals, colouring matters, remedies, agriculture, and manufactures.

Towards the end of the eighteenth, and at the commencement of the nineteenth centuries, chemistry was established upon a durable basis, after having floated during nearly two thousand years amongst mystical, obscure, and incoherent notions. It was a Frenchman, Lavoisier, who fixed these indecisive ideas, by the definite principle of the stability of matter, invariable in the nature and weight of its simple bodies. Perhaps, as has been asserted, Lavoisier did not discover any particular fact ; but, according to Aristotle, principles and causes are things which are of more scientific importance, for by them we arrive at other knowledge. Now Lavoisier discovered the fundamental principle of chemistry; the science dates from him.

Is this saying that Lavoisier divined all, perceived all, traced for all time the plan of chemical science? Not at all; no more than that Newton alone founded astronomy. For this the in. evitable concourse of the great nations was required. Whilst Lavoisier published his immortal researches, the English Priestley and Cavendish discovered the principal gases and the nature of water-inventions that were seized immediately by Lavoisier to support his theory. The Swedish Scheele brought also his precious contingent to the common work. Some years afterwards, an Englishman of genius, Humphry Davy, completed the edifice by the discovery of the alkalme metals, which he obtained by the application to chemical decompositions of the pile recently discovered by a great Italian, Volta.

Germany equally marked its place in the foundation of the new science. It was in the law of numbers that its work was principally characterised : Richter, Wenzel, and the great Berzelius (a Swede) established the law of chemical equivalents, that is to say, a law as general and as absolute in chemistry as the law of Newton in astronomy. It is remarkable that the part of the Germans in this discovery has been principally experimental and practical, contrary to the opinion generally received of German genius. On the contrary, the atomic theory, properly so-called, of a character more abstract and more litigious, is due to an Englishman, Dalton; whilst its demonstration by the physical study of the gases has been accomplished by a Frenchman, Gay-Lussac. This shows that the geniuses of the European races are not so different as has been asserted. Give them a common and equally high culture, and from each will proceed inventions equally original.
This conjunction of Germany, France, and England is to be seen in every great epoch in the history of modern science. The demonstration could be carried down to the present time, proving that neither of these three nations has degenerated from its past : the doctrine of substitutions, the theory of the ethers, that of the polyatomic alcohols, dissociation, the idea of organic ferments, the methods of synthesis of organic principles, have been principally established by French discoveries; the theory of the radicals and that of the polyatomic elements are rather to be attributed to German discoveries; whilst the electro-chemical theory and the methor of double decompositions have been in vented in England. Finally, the great doctrine of the equivalence of the natural forces, more particularly designated under the name of the mechanical theory of heat, was first discerned by a German, Mayer, and an Englishman, Joule. Developed afterwards by a German mathematician, it has been established in chemistry principally by the experiments of French, English, ancl Danish scientific men. But it would not be wise to dilate upon the science of the present day; we are too near to it, and are too much engaged in it, for any estimate to escape suspicion of partiality.

In looking back over this short sketch of the progress of the science with which I am best acquainted, I would not ignore the part of Italy, which in the past was so great (may it resume its importance in the future!), nor that of the United States, nor of Russia. But, I repeat, the initiative of the ideas and discoveries has rested for more two centuries in the bosom of three nations -English, French, and German. Their union and their reciprocal sympathy is indispensable, under the penalty of a general loss to civilisation.

\section{INSTRUCTIONS FOR PREPARING BIRDS $E G G S$ *}

I WISH to say a few words for the benefit of those engaged in collecting öological specimens.

Twenty years ago all eggs were blown with two holes-one at each end, and until within ten years most eggs have been emptied with two holes as above, or at the side. Very many of the eggs which I now receive in my exchanges are similarly prepared. At the present time no experienced collector ever makes but one hole to remove the contents of the egg, using a blowpipe in some form to accomplish this object. The following rules should invariably be followed:-

I. Prepare your eggs neat and clean. There is no excuse for having a dirty set of eggs where water, soap, and a tooth-brush can be found. Some eggs will not bear washing, as the shell is so calcareous that the characteristic markings will wash away. There are, however, but few of this class, and I believe this peculiarity is confined to the water-birds. You can see it in any of the species (Smithsonian Catalogue) from 615 to 628 inclusive, and also in the eggs of the Grebes and Flamingo, and some others. Having once seen it you will never mistake it for anything else.

2. Make but one hole, and that a small one in the middle of the egg ; cover this hole, when the contents are removed, and the specimen is dry, with gold-beater skin or the paper number indicating the bird. Use an egg drill or a pointed wire of four or six sides to make the opening.

3. If the blowpipe does not readily remove the contents of the egg, inject water and shake the specimen thoroughly, then blow again, and repeat the operation until every particle of the egg is removed.

4. If the embryo is too far advanced to remove through a moderate sized hole, blow out what you can of the liquid part and fill the egg with water, wipe it dry and put it away in a covered box in some warm place, and every twenty-four or fortyeight hours shake it well and remove what you can, and then refill with water. Repeat this operation several times, and after a few days the contents will become sufficiently decomposed to take away.

5. After removing the contents of any egg, cleanse the shell thoroughly. Fill it with clean water and shake vigorously, blow out the contents and repeat the operation until the specimen is perfectly clean. This is particularly desirable in white eggs, as black spots will show through the shell after a time if the least particle of the egg or blood stains remains inside.

* Ey William Wood, M.D. Reprinted from the American Naturalist. 